\title{
UM MUNDO DE PAPEL - REFLEXÕES SOBRE \\ O REALISMO DE LUIZ RUFFATO
}

\author{
A "PAPERWORLD" - CONSIDERATIONS ABOUt \\ THE REALISM OF LUIZ RUFFATO \\ Karl Erik Schøllhammer
}

PUC-Rio

Rio de Janeiro- Brasil

\section{Resumo}

A partir do romance Flores artificiais, de Luiz Ruffato, o ensaio discute uma radicalização nas demandas do real na literatura brasileira contemporânea, em busca de outro fundamento para um realismo contemporâneo sustentado por falas e escritos de personagens que já não são representados literariamente, mas apropriados e incluídos em sua própria materialidade. Tais dispositivos precisam ser entendidos à luz do que Jacques Rancière chamou de "regime ético da imagem", na medida em que procuram expressóes que são ontologicamente determinadas pelo real solicitado.

Palavras-chave: Flores Artificiais; realismo; regime ético da imagem.

\section{Resumen}

A partir de la novela Flores artificiais, de Luiz Ruffato, este ensayo discute la radicalización que se ha operado en las demandas de lo real en la literatura contemporánea, en busca de otro fundamento para un realismo contemporáneo, sustentado en la recuperación de expresiones y escrituras de personajes que ya no son representados literariamente, sino apropiados e incluidos en su propia materialidad. Tales dispositivos precisan ser entendidos a la luz de lo que Jacques Rancière llamó de "régimen ético de la imagen", en la medida que procuran expresiones que son ontológicamente determinadas por lo real solicitado.

Palavras-claves: Flores Artificiais; realismo; régimen ético de la imagen.

\section{Abstract}

From the example of the romance Flores Artificiais, by Luiz Ruffato, this essay will discuss the radicalization of the "demands of the real" in contemporary Brazilian literature in search for another fundament for a realism sustained in the discourse and writings of characters not represented by literature but appropriated and included in their own materiality. Such apparatus needs to be understood in light of what Jacques Rancière called The Ethical Regime of Images, insofar they search for expressions determined ontological by the real in question.

Keywords: Flores Artificiais; realism; ethical regime of image. 
Todos os meus livros, de uma forma ou de outra, tratam de uma única questão: o desenraizamento. Este tema principal está presente em Eles eram muitos cavalos, está presente no De mim já nem se lembra [...] e está presente no projeto Inferno provisório. O que houve é que em Estive em Lisboa e lembrei de você ampliei esse olhar acompanhando o personagem, um imigrante brasileiro, no exterior. Até então, havia me dedicado a entender este processo de desenraizamento dentro do Brasil. Com Estive em Lisboa e lembrei de você, comecei a perfazer esse novo caminho, que em Flores artificiais eu aprofundo. (RUFFATO, 2014)

Na tradição da literatura moderna, um dos traços significativos no reconhecimento da nova autonomia que caracteriza a literatura como distinta das belas-letras foi a metaliteratura. O livro aparecia de referência interna para o livro, e a ficção virava protagonista da própria ficção, numa recursividade que tomava a literatura como tema para a literatura. Reconhecemos este tipo de metaficcionalidade desde Cervantes e Shakespeare e dos inúmeros exemplos de Luigi Pirandello a Jorge Luis Borges, no auge do modernismo literário. $\mathrm{O}$ efeito de metaliterariedade que se criava quando o livro era representado dentro do próprio livro era interpretado como um questionamento inquietante das fronteiras entre realidade e ficção. Provocava uma impressão de realização do enredo como estrutura determinante para os heróis em busca da verdade e simultaneamente ficcionalizava os acontecimentos contingentes do real. Exaltava-se assim a realidade da poesia e da narrativa cuja força podia encantar o mundo profano e semeava-se ao mesmo tempo uma dúvida a respeito dos limites convencionais da ficção diante da realidade. De certa maneira, foi esse efeito metaliterário que virou sinônimo de literariedade, na medida em que provocava uma experiência de autonomia que na modernidade identificaria sua realidade estética.

Nos últimos livros do mineiro Luiz Ruffato, o autor cria um jogo metaficcional peculiar que procura dar outra orientação à lógica modernista, ainda que estruturalmente, em uma primeira leitura, possa ser identificada aquela. Em De mim já nem se lembra, de 2007, Ruffato supostamente reescreve as cartas que seu irmão José Célio enviara para a mãe, Geni. Em 2009, dentro do projeto editorial Amores expressos, publica Estive em Lisboa e lembrei de você, romance que alega ser a transcrição de uma longa entrevista, gravada em quatro sessóes, com Sérgio de Souza Sampaio, trabalhador de Cataguases que migrara para Lisboa. Mais recentemente, em 2014, lançou o romance Flores artificiais, que se apresenta como transcrição e edição parcial de um longo manuscrito enviado ao autor por um tal de Dório Finetto, nascido na cidade mineira de Rodeiro e cuja família aparentemente teria laços com os 
Ruffato, relação que teria motivado o engenheiro a mandar seus escritos a Luiz Ruffato a fim de que este aproveitasse "alguns temas". Nos três exemplos mencionados, o autor parece abrir mão da prerrogativa de "criador", alegando a existência de documentos não literários que lhe servem de fundamento. A estrutura de Flores artificiais é bastante peculiar e causou certa perplexidade entre os críticos quando foi lançado. O prefácio explica as circunstâncias do encontro entre dois escritores, o amador Dório Finetto e o profissional Luiz Ruffato, em decorrência de duas experiências anteriores com entrevistas gravadas e cartas enviadas ao romancista, que nessas ocasióes se colocou a disposiçáo para reescrever, organizar e editar a fala do outro. Em seguida é reproduzida a carta de Finetto que acompanhara o manuscrito, na qual ele relata a crise depressiva que sofreu por passar a virada do século em seu apartamento na praia do Flamengo depois de mais de 20 anos vivendo no exterior como consultor do Banco Mundial. Parte do tratamento indicado por sua psicanalista fora relatar a própria história escrevendo um conjunto de histórias, contos, todos situados no exterior e relatando encontros entre Finetto e outros personagens nesta parte do livro intitulado Viagens à terra alheia. ${ }^{1}$ Depois de oito histórias, cujo conjunto é dedicado a Luiz Ruffato e à psicanalista Regina Gazzola, segue um "Memorial descritivo" da biografia de Dório Finetto, assinado por Luiz Ruffato, que assim aparece como genuíno autor dessa parte, que Finetto, por sinal, não aprovou.

Não surpreende que uma construção táo complexa tenha despertado leituras que procuravam mostrar o jogo metaficcional segundo o padrão moderno da procura do manuscrito original, ou então leituras que viram a brincadeira centrada na vontade do autor de desaparecer atrás do surgimento do personagem-autor Luiz Ruffato, que assume o papel de simples escriváo a serviço dos verdadeiros "autores", a saber, os homens comuns que vivem e experimentam as narrativas que forjam a matéria-prima para os romancistas profissionais.

Aqui, primeiro discuto a construção ficcional das referências do romance, e em seguida, abordo a singular inversão de ponto de vista que abre uma visão reflexa da inserção do Brasil contemporâneo no processo da globalização. Sugiro inicialmente que Ruffato aplica o jogo metaliterário no sentido inverso da experiência modernista e, em vez de salientar a autonomia do literário que vai caracterizar a modernidade em geral, procura outro fundamento para um realismo contemporâneo que já não se sustenta sobre a verossimilhança descritiva, e sim sobre falas e escritos de personagens que não são mais representados literariamente, mas apropriados e incluídos em sua própria materialidade, apesar de certas acomodaçóes estilísticas - "assunto demandando estilo" (10)

\footnotetext{
${ }^{1}$ Inspirado talvez no Viagens na terra alheia, livro de Teixeira de Vasconcellos publicado em 1863.
} 
-, pois, como Finetto pedira, o escritor "envernizou a trama” segundo os "próprios predicados”. Não interessa discutir se esse jogo é real ou ficcional, se os personagens desses três livros existem ou não fora da ficção nem se o próprio Ruffato, aqui, deve ser considerado autor, autor implícito ou personagem, ou as três coisas ao mesmo tempo. Para meu argumento, é mais interessante questionar o deslocamento operado dentro das opçôes metaliterárias oferecidas pela tradição para provocar um efeito de realismo em função da referência textual assim criada. Podemos, em outras palavras, ver nessa experiência um apagamento da fronteira entre ficção e documentarismo, compreensível para um realismo em moldes históricos, ainda que a demanda aqui seja mais radical, pois sugere uma escrita em relação de compromisso com seu objeto, neste caso um outro discurso, com o qual indica uma espécie de laço essencial e ontológico, numa busca da verdade. Já no romance Eles eram muitos cavalos, Ruffato cria um estilo experimental que mistura a deformação da expressão com a verossimilhança mimética da realidade metropolitana, mesclando assim a liberdade modernista ao constrangimento realista. $\mathrm{O}$ autor inclui fragmentos textuais recolhidos na rua junto aos transeuntes, pedaços de papel, títulos de livros à venda, santinhos e outros estilhaços duros de textos e palavras que apareciam como índices de uma realidade não necessariamente representada pelo romancista, mas inserida em sua materialidade bruta no texto de criação. Em outro texto, caracterizei essa técnica como realismo indexical (SCHØLLHAMMER, 2012), certamente parte de uma tendência contemporânea que opera dentro da impossibilidade de distinguir com clareza entre a realidade e suas imagens, representaçóes, simulacros.

$\mathrm{Na}$ versão atual da mesma apropriação do texto alheio, o dispositivo de inclusão já não funciona na excepcionalidade da introdução do extralinguístico. Neste caso, a possibilidade do realismo existe em função de uma referência concebida como uma espécie de língua espontânea, bruta e vital que palpita por trás de sua transcrição literária. Se o realismo histórico estava profundamente ligado à literatura moderna enquanto expressão de um novo regime estético das artes, como mostrou Jacques Rancière (RANCIÈRE, 2010: 75-90), o projeto de Ruffato corrobora a tendência contemporânea de retomar técnicas literárias provenientes daquilo que Rancière chamou de regime ético da imagem, na medida em que procura expressões que são ontologicamente determinadas pelo real solicitado. Trata-se de um realismo preocupado com a origem da imagem criada, sua referência, e nesse sentido salienta a questão da verdade, por um lado, e a de seus usos e efeitos, por outro. A insistência sobre a factualidade do narrado, as referências autobiográficas, os traços documentais recorrentes, a tematização da técnica e do fazer sempre subordinado ao conteúdo a ser depurado pelo escritor, tudo isso abre mão 
da finalidade literária, do literário enquanto experiência estética, em nome de um desafio e de um compromisso a ser cumprido.

O conceito de regime de arte basicamente caracteriza a relação entre os modos de pensamento, a escrita e a imagem e a realidade de determinado momento histórico. Trata-se de uma distribuição do sensível, diz Rancière, que demarca o que se torna visível e dizível, mas é um conceito sempre desafiado pelas próprias contradiçóes e pela relaçâo tensa que se estabelece entre os regimes. É bastante conhecida a distinção que Rancière oferece na análise da modernidade, uma palavra que ele evita, em função de basicamente três regimes das artes: um regime ético, vinculado a uma compreensão da imagem similar à compreensão de Platáo; um regime representativo ou poético, com base na análise desenvolvida por Aristóteles da poética narrativa; e, finalmente, um regime estético, identificado com a autonomia do estético, da sensação e do efeito poético nas artes da alta modernidade, na literatura iniciada de modo singular com a poesia de Mallarmé e a narrativa de Flaubert, magistralmente representada no romance Madame Bovary, em que experimentalismo e realismo se encontram e se conciliam de modo exemplar.

Não devemos entender os três regimes como tentativa de periodização; ainda que o estético surja historicamente com indicaçóes mais precisas do que os outros dois regimes em questáo, trata-se de um conceito meta-histórico. Se interpretamos a proposta de Rancière em diálogo com a análise feita por Erich Auerbach do realismo na literatura ocidental, podemos reconhecer que, assim como Auerbach detecta índices do realismo histórico do século XV na descrição do cotidiano e da realidade comum e sem nobreza já em Homero e no Velho Testamento, assim também podemos reconhecer os detalhes descritivos sem funcionalidade narrativa que, para Roland Barthes (2005), eram os indicadores de um "efeito de real" que caracteriza a ligação simbiótica entre autonomia e realismo do regime estético. Onde Auerbach percebe certa continuidade durante mais de dois milênios na inserção de detalhes do cotidiano comum, Rancière interpreta o mesmo fenômeno à luz de um processo de democratização que, ao romper com os princípios hierárquicos dos gêneros clássicos, possibilita a liberação do prazer estético e a ampliaçáa do escopo do que poderia ser visto e dito na literatura moderna e justificar a centralidade do projeto realista. Rancière descreve o realismo romanesco como "antes de tudo a subversão das hierarquias da representação (o primado do narrativo sobre o descritivo ou a hierarquia dos temas) e a adoção de um modo de focalização fragmentada, ou próxima, que impóe a presença bruta em detrimento dos encadeamentos racionais da história" (RANCIÈRE, 2005: 35). Devemos entender os três regimes contemporaneamente, existentes com certa simultaneidade e anacrônicos na medida em 
que possibilitam o ir e vir de formas representativas de diferentes momentos históricos. Nesse sentido, falar de uma retomada de traços do regime ético não sugere uma volta às formas clássicas da poesia, mas sim a demanda de uma outra relação da literatura com o mundo, que extrapole conceitos de realidade e de verdade no domínio escorregadio do fazer literário contemporâneo. É a partir dessa perspectiva que deve ser entendido o que foi caracterizado como a "volta do real" (FOSTER, 1990), não só como a aparição de obras de arte cujas expressóes extremas ameaçavam romper com noçóes modernas de representação, mas como um movimento mediático mais amplo que mistura de alhos e bugalhos: reality shows e cinema-verdade, pseudodocumentarismo e pós-autonomia, biografismo, autoficção e autoajuda, traumatofilia, confessionalismo e outras formas de pieguice e bisbilhotice. Sob o impacto dessa tendência geral, o desafio para a literatura contemporânea fica mais agudo e a retomada do projeto realista vira um campo minado em que qualquer movimento bem-intencionado pode implodir em sentimentalismo e ingenuidade. Exigir das palavras e das histórias que sejam reais e verdadeiras é um gesto nada gratuito que requer muita cautela e que deve se realizar com o frescor do inédito e do experimental.

A primeira proposta a observar na escrita de Ruffato, identificada desde seus primeiros contos, em Histórias de remorsos e rancores (1998) e Os sobreviventes (2000), é a valorização do coloquial e da oralidade, que marca um determinado falar regional ricamente sustentado por uma semântica nada casual, e sim identificada nos traços históricos, culturais, sociais e geográfi$\cos$, facilmente reconhecidos. Aqui, Ruffato não só recupera e valoriza a tradição realista e naturalista da literatura brasileira como também se associa à oralidade do neorrealismo que caracteriza, por exemplo, o romance de $30 \mathrm{e}$ o regionalismo nordestino e gaúcho. É importante observar, nessa tradição, o deslocamento da ambição realista do descritivismo de um mundo exterior que pode ser nomeado pelo esforço descritivo lançando máo dos discursos científicos e quase científicos necessários para uma representação literária que toma a própria linguagem como objeto. Não se trata de uma descrição dos objetos e das açôes de um mundo diante com o qual o escritor se depara; trata-se sim de um descobrimento da linguagem que já habita este mundo e que se torna o objeto da representação literária. Uma referência que oferece a real possibilidade de imitação, já que uma palavra pode sim imitar fielmente uma palavra, mesmo que essa imitação ou reprodução da aplicaçáo da palavra e do desenrolar da frase agora seja feita por escrito. É claro que esse deslocamento da referência na realidade para sua expressão linguística é apenas uma das contradiçóes do realismo histórico e faz parte da autonomia que caracteriza o regime estético. Para Rancière, a liberação da expressão literária de sua 
determinação pelas regras das poéticas clássicas, que definem os regimes éticos e representativos, é parte da democratização política trazida pelas revoluçóes do século XIX. Da perspectiva do regime ético identificado por Ranciere no livro X da República de Platão, a palavra é, em sua materialidade expressiva, ontologicamente subordinada à ideia em estado de pensamento e também à materialidade sensível dos objetos. $\mathrm{Na}$ Poética de Aristóteles, encontramos a base do regime representativo ou poético num elaborado sistema hierárquico de controle que se expressa de modo magistral nos gêneros e seus conteúdos altamente hierarquizados. Para personagens e assuntos superiores aos dos homens comuns, as formas apropriadas são a tragédia e a epopeia; para os inferiores ou iguais, servem a comédia e a sátira. $\mathrm{O}$ romance surge exatamente ao mesmo tempo que a emergente prevalência desses conteúdos humanos e ordinários do cotidiano realista, que já para Erich Auerbach constituem a Mimesis germinal da modernidade (AUERBACH, 2004).

O regime estético foi resultado da liberação dos conteúdos do sistema hierárquico previsto pelo sistema representativo; qualquer conteúdo podia ganhar a nobreza da forma, antes um privilégio restrito a alguns. Assim, a liberação formal das expressóes literárias vinha acompanhada de uma democratização dos conteúdos, que vinculavam a política à estética de modo intrínseco, como uma nova visibilidade do que era reconhecido como real.

Quando Ruffato e alguns de seus contemporâneos retomam os preceitos do realismo histórico, reacendem as contradiçóes do regime moderno, como suas tensões com os elementos éticos e representativos, que nunca foram totalmente abandonados. Sempre se manteve na literatura moderna um fundamento representativo na organização narrativa, mesmo livre de seus enredos e mesmo com as possibilidades expressivas na materialidade da linguagem. Da mesma maneira, a crença numa idealidade platônica dos princípios que guiam a racionalidade lógica das açôes também acompanha a literatura e as artes modernas e contemporâneas como uma insistência em algo mais verdadeiro e real por trás daquilo que semioticamente parece mera convenção. No regime representativo, o princípio mais importante é a estrutura ficcional e narrativa; a linguagem e a poeticidade ocupam o lugar principal, e com elas se consolida o predomínio do texto sobre a imagem. No regime estético, a imagem se impóe sobre o texto, e a descrição, sobre a narratividade. Ainda que sejam o literário ou o poético que vão definir a literatura como diferente das outras artes, ela encontra sua potência na expressividade das palavras, e não mais em sua estruturação como enredo narrativo. No regime estético as palavras já não são unicamente instrumentos para dar voz a uma verdade anterior; elas encontram a verdade em sua própria expressividade, e não apenas na elaboração de uma história. $\mathrm{O}$ argumento aqui é que exatamente este 
ponto é a contradição não resolvida entre o representativo e o estético, entre a prevalência do enredo e a autonomia da expressividade poética, que já no início do século XX motiva uma virada no realismo histórico, dando ênfase à referência da linguagem oral. Surge a escrita de um realismo que agora pode abrir mão de procurar o equilíbrio adequado entre narrativa e descrição, dificuldade discutida por Lukács, para salientar a expressividade do oral como criatividade que atualizava a figuratividade convencional do léxico e dinamizava sensivelmente o relato em sua estrutura molecular. A estratégia de apropriação do oral é fácil de reconhecer nos neorrealismos do século XX e no Brasil. O exemplo magistral é a oralidade da escrita de Guimarães Rosa, que ilustra um outro aspecto do dispositivo, a saber, a abundante aplicação de substantivos comuns e próprios, elementos da linguagem que puxam a convencionalidade linguística para os índices de seres e coisas concretas, que aparecem como uma espécie de referência dêitica do discurso, do mesmo modo como uma marca dialetal pode marcar um laço não arbitrário do usuário da linguagem convencional. Percebe-se que já nesta estratégia meramente representativa subjaz uma insistência nos possíveis elos "reais" entre a coisa e a palavra, entre a linguagem e o mundo, como se fosse de alguma maneira possível na literatura rever o ato inicial da nomeação adâmica e de modo performativo qualificar o específico dessa realidade, resguardando as marcas que a identificam e designam, por um lado, e, por outro, recriando ficcional e esteticamente seu processo virtual, seu devir e sua potência. Para Ruffato, autor propenso à construção de grandes narrativas, como o romance proletário Inferno provisório, em cinco volumes, a oralidade regional traz consigo certa identidade cultural e social que se expressa na dinâmica sintática e no desdobramento do raciocínio coloquial, reconstruído na escrita, que sempre foi um traço de seu singular regionalismo. A opção, nos livros mais recentes, por uma aparente estratégia de apropriação direta do texto ou do discurso do outro deve ser tomada como um aprofundamento nessa contradição do realismo contemporâneo.

Se o "efeito de real", para Roland Barthes, era consequência do detalhe insignificante e aparentemente supérfluo, Ruffato procura um índice do real na relação construída entre a figura do autor e sua relação com o texto. A apariçáo do autor enquanto personagem é, neste caso, mais que um traço autobiográfico ou um sintoma de autoficção, seguindo a moda contemporânea brasileira; antes parece ser parte de uma série de detalhes que tendem a suspender o pacto ficcional e criar um contínuo entre marcas documentais e dispositivos ficcionais, uma zona indistinguível - uma "realidadfcción", nas palavras de Josefina Ludmer - entre a criação literária e suas referências circunstanciais (LUDMER, 2007). Se o autor insere assim seu lugar na ficção 
como um operador da realidade indicada, vale a pena num segundo passo da leitura questionar a fisionomia da realidade em questâo. Lembremos que o personagem fundamental é o narrador, Dório Finetto, supostamente o autor do manuscrito inicial, apresentado por meio de oito relatos cujo conjunto se denomina Viagens na terra alheia. Finetto fala em seu próprio nome e conta pouco de si; os relatos são pautados por encontros com outros personagens com os quais ele depara em suas andanças pelo mundo e cujas histórias tem interesse em contar. No primeiro conto, "Uma história inverossímil”, conhecemos Bobby, ou Robert William Clarke, numa narrativa que ainda traz descriçóes da infância e da juventude de Finetto. Bobby nasceu em Southhampton, mas passou a infância no Brasil e, depois de uma vida marcada pela participação nas guerras coloniais inglesas na África, acaba em Juiz de Fora como especialista em veneno de ratos, procurando em vão a mulher que ama. No conto "O presente absoluto", o narrador encontra uma francesa em Buenos Aires - mulher casada, mãe de dois filhos e professora aposentada - em busca da sensualidade do tango. E no relato "El Gordo" o encontro é com um uruguaio que carrega um pesado segredo sobre o fato de ter sido abandonado pelo pai, que foge para o Brasil sob o pretexto de fugir da ditadura, mas na verdade vai atrás de outra mulher. Em "Comer sushi em Beirute", o tema também é a ditadura, desta vez a argentina, relatada pelo cientista político Marcelo, que foge da pátria nos primeiros dias depois do golpe e nunca mais volta. A maioria dos personagens é formada por estrangeiros que, como ele, relatam a Finetto suas experiências fora do lar. No capítulo "Susana", Alexandre conta a história da bela portuguesa Susana Souza, que parece fugir da própria beleza e depois de uma experiência traumática como voluntária na África acaba desaparecendo no Timor, provavelmente se suicidando. Outros, como a mulher de Havana ou a dona de hotel de Hamburgo, são encontros de viagem que catalisam as reflexôes do narrador e espelham, cada um a sua maneira, questóes ligadas ao desterro. Assim se constrói um duplo perspectivismo em que a relação dialógica entre o narrador, Finetto, e seus encontros reflete a experiência global do ponto de vista de quem não está nem no centro da visão hegemônica da cultura ocidental nem na sua periferia brasileira, onde o narrador perde sua identidade depois de duas décadas de trabalho no exterior. Cria-se desse modo uma imagem ficcional da realidade que não é a visão exterior de quem descreve o Brasil de fora, procurando suas distinçóes exóticas, nem um reflexo do olhar do brasileiro viajante que compara o que experimenta fora com aquilo que normalmente vive motivado por algum desejo de inserção ou de "atração do mundo", como formulou Joaquim Nabuco. Aqui, os encontros de Finetto são em sua maioria com pessoas que vivem o desterro na periferia da periferia. Sendo os 
relatos centrados em encontros de viagem, a ficção passa a ser uma maneira de pensar o mundo, de imaginar e projetar o mundo globalizado e abandonar as contençóes particulares de um realismo amarrado à experiência local ou nacional. Nesse sentido, estamos diante de um caso particular do que foi definido como uma "romanceação do global" (SISKIND, 2014), contrapartida da globalização do romance, e que se caracteriza pela produção de imagens de um mundo globalizado. Em lugar de produzir ou reproduzir os discursos de aventura universais a partir de uma perspectiva de um mundo a ser conquistado, Flores artificiais reflete uma perspectiva global totalmente esfacelada, fragmentária e disfórica de personagens em profundo desespero e em busca de alguma afirmação numa existência em que nem a nacionalidade nem o cosmopolitismo oferecem identidades plausíveis. Numa situação em que grande parte da literatura brasileira exibe sua desenvoltura no mundo globalizado com uma frequência alta de relatos de viagem, de aventuras e conquistas em países estrangeiros - como no projeto Amores expressos -, agora destinos ao alcance de um viajante competente e com dinheiro no bolso, as histórias narradas por Ruffato flagram o lado da solidão e do desarraigamento dos encontros de viagem. Já no romance Estive em Lisboa e lembrei de você o relato girava em torno do desapontamento das grandes expectativas do personagem principal diante das expectativas ingênuas de um trabalhador do interior de Minas Gerais. Ainda assim a ficção criava a imagem de um Portugal vivido pelo narrador com uma geografia reconhecível e uma ideia de certa maneira previsível dentro do imaginário popular brasileiro do que seja esse país tão próximo da história do Brasil. Em Flores artificiais desaparece a geografia literária reconhecível, e o encontro com o outro se dá numa topografia espacial e geográfica incerta, cujas caraterísticas descritivas se tornam fantasmagóricas, sustentadas apenas por traços aleatórios dos diálogos tramados e por uma narrativa muito discreta das açóes dos personagens, que ainda assim refletem razóes e afetos que convencem e comovem.

\section{Referências bibliográficas}

AUERBACH, Erich. Mimesis: a representação da realidade na literatura ocidental. São Paulo: Perspectiva, 2004.

BARTHES, Roland. "O efeito de real". In: O rumor da língua. São Paulo: Martins Fontes, 2005: 181-90.

LUDMER, Josefina. "Literaturas postautónomas 2.0", Ciberletras - Revista de crítica literaria y de cultura, n. 17, jul. 2007. Disponível em: <http://goo.gl/dk4hpv>. Acesso em: 20 nov. 2015.

RANCIÈRE, Jacques. "O efeito da realidade e a política da ficçáo", Novos Estudos Cebrap, São Paulo, n. 86, mar. 2010. 
. A partilha do sensivel. São Paulo: Editora 34, 2005: 35.

RUFATTO, Luiz. Luiz Ruffato mescla realidade e ficção em seu novo livro. [14 de junho, 2014]. São Paulo: O Estado de S. Paulo. Entrevista concedida a Ubiratan Brasil.

SISKIND, Mariano. Cosmopolitan Desires: Global Modernity and World Literature in Latin America. Chicago: Northwestern University Press, 2014.

SCHØLLHAMMER, Karl Erik. "Realismo afetivo: evocar realismo além da representação”, Estudos de Literatura Brasileira Contemporânea, Brasília, n· 39, jan./jun. 2012. Disponível em: <http://goo.gl/ETteup >. Acesso em: 20 nov. 2015 .

Karl Erik Schøllhammer é professor associado e Diretor do Departamento de Letras da PUC-Rio. Pesquisador com bolsa de produtividade do CNPq é Cientista do Nosso Estado da FAPERJ. É autor, coautor e editor de vários livros, entre eles: Linguagens da violência (2000), Novas epistemologias (2000), Literatura e mídia (2002), Literatura e cultura (2003), Literatura e imagem (2005), Literatura e memória (2006), Henrik Ibsen no Brasil (2008), Literatura e critica (2009) e Literatura e realidade(s) (2010), Atrocity Exhibition (2011), Memórias do presente (2012), Cenas contemporâneas da escrita (2014) e Literatura e espaços afetivos (2014). De autoria integral os títulos mais recentes são Além do visivel: o olhar da literatura (2007), Ficçâo brasileira contemporânea (2009, 2011) e Cena do crime (2013).

E-mail: karlerikschollhammer@me.com

Recebido em: 15/01/2016 Aprovado em: 30/01/2016 